\title{
Loss of IL-10 Promotes
} \section{Differentiation of Microglia to a M1 Phenotype}

\author{
Björn Laffer ${ }^{1,2}$, Dirk Bauer ${ }^{1}$, Susanne Wasmuth ${ }^{1}$, Martin Busch ${ }^{1}$, Tida Viola Jalilvand ${ }^{1,3}$, \\ Solon Thanos ${ }^{3}$, Gerd Meyer zu Hörste ${ }^{4}$, Karin Loser ${ }^{5}$, Thomas Langmann ${ }^{6}$, \\ Arnd Heiligenhaus ${ }^{1,7+}$ and Maren Kasper ${ }^{1 *+}$
}

\begin{abstract}
' Department of Ophthalmology and Ophtha-Lab at St. Franziskus-Hospital, Münster, Germany, ${ }^{2}$ Department of Ophthalmology, University of Duisburg-Essen, Essen, Germany, ${ }^{3}$ Department of Experimental Ophthalmology, Westphalian Wilhelms University of Münster, Münster, Germany, ${ }^{4}$ Department of Neurology with Institute of Translational Neurology, University Hospital Münster, Münster, Germany, ${ }^{5}$ Department of Dermatology - Experimental Dermatology and Immunobiology of the Skin, University of Münster, Münster, Germany, ${ }^{6}$ Laboratory for Experimental Immunology of the Eye, Department of Ophthalmology, University of Cologne, Faculty of Medicine and University Hospital Cologne, Cologne, Germany, ${ }^{7}$ University of Duisburg-Essen, Essen, Germany
\end{abstract}

\section{OPEN ACCESS}

Edited by:

Stefania Ceruti,

University of Milan, Italy

Reviewed by:

Maria Antonietta Panaro, University of Bari Aldo Moro, Italy

Leyre Mestre,

Cajal Institute (CSIC), Spain

*Correspondence: Maren Kasper maren.kasper@uveitis-zentrum.de

tThese authors have contributed equally to this work and share last authorship

Specialty section:

This article was submitted to Non-Neuronal Cells,

a section of the journal

Frontiers in Cellular Neuroscience

Received: 22 May 2019 Accepted: 09 September 2019 Published: 09 October 2019

Citation:

Laffer B, Bauer D, Wasmuth S, Busch M, Jalivand TV, Thanos $S$, Meyer zu Hörste G, Loser K, Langmann T, Heiligenhaus $A$ and Kasper M (2019) Loss of IL-10 Promotes Differentiation of Microglia to a M1 Phenotype. Front. Cell. Neurosci. 13:430. doi: 10.3389/fncel.2019.00430
Microglia represent the primary resident immune cells of the central nervous system (CNS) and modulate local immune responses. Depending on their physiological functions, microglia can be classified into pro- (M1) and anti-inflammatory (M2) phenotype. Interleukin (IL)-10 is an important modulator of neuronal homeostasis, with anti-inflammatory and neuroprotective functions, and can be released by microglia. Here, we investigated how IL-10 deficiency affected the M1/2 polarization of primary microglia upon lipopolysaccharide (LPS) stimulation in vitro. Microglia phenotypes were analyzed via flow cytometry. Cytokine and chemokine secretion were examined by ELISA and bead-based multiplex LEGENDplex ${ }^{T M}$. Our results showed that genetic depletion of IL-10 led to elevated M1 like phenotype (CD86+ CD206-) under proinflammatory conditions associated with increased frequency of IL-6+, TNF- $\alpha+$ cells and enhanced release of several pro-inflammatory chemokines. Absence of IL-10 led to an attenuated M2 like phenotype (CD86-CD206+) and a reduced secretion of TGF- $\beta 1$ upon LPS stimulation. In conclusion, IL-10 deficiency may promote the polarization of microglia into M1-prone phenotype under pro-inflammatory conditions.

Keywords: cytokines, phenotype, interleukin-10, microglia, M1/2 polarization, lipopolysaccharide

\section{INTRODUCTION}

Microglia are yolk sac-derived myeloid lineage cells (Kierdorf et al., 2013) that are commonly defined as innate immune cells in the CNS. Under homeostatic conditions, predominantly ramified and resting microglia screen their microenvironment to detect injury or infection and act to surveil the CNS by removing cell debris and contributing to neuronal plasticity (Davalos et al., 2005; Nimmerjahn et al., 2005).

Abbreviations: CCL, chemokine (C-C motif) ligand; CD, cluster of differentiation; CNS, central nervous system; CX3CL, chemokine (C-X3-C motif) ligand; EAE, experimental autoimmune encephalomyelitis; ELISA, enzyme-linked immunosorbent assay; IFN- $\gamma$, interferon gamma; IL, interleukin; KO, knock out; LPS, lipopolysaccharide; M-CSF, macrophage colony-stimulating factor; MS, multiple sclerosis; TGF- $\beta$, transforming growth factor beta; TNF- $\alpha$, tumor necrosis factor-alpha; WT, wild type. 
Under inflammatory conditions, microglia are the main local producers of cytokines in neuronal tissues (Hanisch, 2002). This surveillant/non-polarized phenotype is also known as M0, which describes non-activated microglia (Ohsawa and Kohsaka, 2011). They assume an amoeboid shape, proliferate, and migrate to the site of damage (Kreutzberg, 1996; Davalos et al., 2005). Upon disturbance of tissue homeostasis or injury, microglia became activated. Owing to their capability to switch between pro(M1) and anti-inflammatory/neuroprotective (M2) phenotypes, they can modulate local immune responses depending on the environment, similar to the macrophage M1/2 classification (Martinez et al., 2009; Fernandes et al., 2014). Microglial activation has been characterized by a number of phenotypes classically described for macrophages (Gordon, 2003).

The M1 phenotype (classical, activated microglia) can be induced by LPS or IFN- $\gamma$ (Hanisch, 2013; Branchi et al., 2014; Orihuela et al., 2016), which is associated with increased production of proinflammatory cytokines/chemokines such as TNF- $\alpha$, IL- $1 \beta$, and CC chemokine ligand CCL2, as well as matrix metalloproteinases (MMPs) and reactive oxygen/nitrogen species (ROS/RNS), among others (Durafourt et al., 2012). Moreover, this neurotoxic phenotype also upregulates high levels of MHC class-II and costimulatory proteins such as CD86 and CD40 (Kalkman and Feuerbach, 2016). The M2 phenotype (alternative, activated microglia) is related to resolving damage (Chhor et al., 2013) and can mainly be induced by IL-4 or IL-13 (Martinez et al., 2008). M2 microglia may include several subtypes, such as M2a (wound-healing and anti-inflammatory, expressing CD206, Fizz1, Arg1, Ym1), M2b (inflammation modulatory, expressing IL10, COX2), and M2c (immunosuppressive, expressing CD163) (Franco and Fernandez-Suarez, 2015; Du et al., 2017). There is increasing evidence that microglia do not show a constant differentiation to an M1 or M2 phenotype, but rather to several phenotypes with high plasticity. Kumar et al. described a mixed transitional phenotype called Mtran, coexpressing M1 markers (iNOS and IL-12) and M2 markers (TGF- $\beta$ and Arg1) (Kumar et al., 2016).

Interleukin-10 is a potent anti-inflammatory cytokine that is produced by both human and murine microglia when these cells are stimulated by LPS and/or IFN- $\gamma$ (Mizuno et al., 1994; Williams et al., 1996; Lee et al., 2002; Seo et al., 2004). IL-10 is an important modulator of glial activation, maintaining the balance between pro- and anti-inflammatory cytokine levels in the CNS. IL-10 is also an important mediator of the crosstalk between microglia, astrocytes, and neurons in the CNS and may be involved in anti-inflammatory (Cianciulli et al., 2015) and neuroprotective effects (Lobo-Silva et al., 2016). Furthermore, it promotes cell survival by expressing anti-apoptotic factors Bcl-2 and Bcl-xl and attenuating caspase 3 activity (Moore et al., 2001).

Administration of IL-10 protected astrocytes from excessive inflammation by inhibiting the production of pro-inflammatory cytokines (Balasingam and Yong, 1996; Ledeboer et al., 2002) and potentiating the production of TGF- $\beta$ by astrocytes (Norden et al., 2014). Furthermore, IL-10 suppressed the production of pro-inflammatory mediators such as IL-1 $\beta$, TNF- $\alpha$, and iNOS and reduced MHC class-II expression in vitro (Aloisi et al., 1999; Ledeboer et al., 2000).
Murine and rat models of EAE are well-established models resembling the pathology of MS in humans. There is evidence from these rodent studies that IL-10 plays an important role in onset, severity, and progression of neuronal inflammatory diseases as shown for EAE. IL-10 KO mice developed a stronger pro-inflammatory $\mathrm{T}$ cell-mediated immune response with more severe EAE and accelerated disease progression compared to WT mice (Samoilova et al., 1998; Anderson et al., 2004). Moreover, human IL-10 (hIL-10) transgenic mice overexpressing IL-10 were highly resistant to EAE (Cua et al., 1999). This effect was mediated by the suppression of Th1 cells and abolished after systemic administration of anti-IL-10 antibody, showing that resistance to disease development was IL-10-dependent (Bettelli et al., 1998). IL-10-mediated suppression of EAE was further shown by administering low IL-10 concentrations via the nasal route, which are associated with decreased microglial activation, T-cell proliferation, and IFN- $\gamma$ secretion (Xiao et al., 1998).

These previous studies demonstrate that treatment with IL-10 plays an important role in modulating inflammatory processes in CNS diseases. Here, we studied the role of IL-10 on the M1/2 phenotype of microglia by isolating brain-derived microglia from WT and IL-10 KO mice and analyzing their cytokine/chemokine response to pro-inflammatory culture conditions.

\section{MATERIALS AND METHODS}

\section{Mice}

C57BL/6J WT (Charles River Laboratories, Wilmington, DE, United States) and C57BL/6J IL-10 knock-out (IL-10 KO) mice (B6.129P2-Il10tm1Cgn/J; Jackson Laboratories, Bar Harbor, ME, United States) (Kuhn et al., 1993) were housed in standard animal rooms under a 12-h light/dark cycle with food and water provided ad libitum. Mice were bred with heterozygote mice and selected for the experiments according to genetic homogeneity.

\section{Isolation of Primary Microglia}

Primary brain derived microglia from WT and IL-10 KO mice (214 days postnatally, female and male) were isolated via magnetic cell sorting. To perform one experiment 5 mice pubs were used per genotype. In brief, postnatal mice were decapitated, brains were isolated and transferred into ice-cold PBS containing 1\% BSA (Carl Roth, Karlsruhe Germany). Brains were minced and enzymatically digested by using Neural Tissue Dissociation Kit - Postnatal Neurons (Miltenyi Biotec, Bergisch Gladbach, Germany). After removing myelin using Myelin Removal Beads II (Miltenyi Biotec), CD11b-positive cells were positively selected by magnetic separation using CD11b (Microglia) MicroBeads, human and mouse (Miltenyi Biotec), according to the manufacturer's instructions. In total 19 experiments were performed. An average yield of $1.5 \pm 0.15 \times 10^{6} \mathrm{CD} 11 \mathrm{~b}+$ cells/mouse brain from WT and $1.6 \pm 0.17 \times 10^{6} \mathrm{CD} 11 \mathrm{~b}+$ cells/mouse brain from IL-10 KO mice were isolated.

\section{Cell Culture}

Primary CD11b-positive brain cells were cultured in 6-well plates $\left(4 \times 10^{5} /\right.$ well $)(\mathrm{TPP}$, Trasadingen, Switzerland) or 
on 8 -well chamber slides $\left(3 \times 10^{4} /\right.$ well) (Merck Millipore, Darmstadt, Germany). Cells were cultivated in DMEM/F12 medium (Biochrom, Berlin, Germany) supplemented with 10\% fetal calf serum (FCS; Biochrom), 1\% penicillin/streptomycin (PAA Laboratories, Pasching, Austria), and 1\% amphotericin B (VWR International, Darmstadt, Germany), and based on other studies (Devarajan et al., 2014; Scheiblich et al., 2017; Voet et al., 2018) 10\% L929 cell (murine fibroblast line, ATCC ${ }^{\circledR}$ CCL-1TM) conditioned medium as a source of growth factors containing 100 $\mathrm{pg} / \mathrm{ml} \mathrm{M}$-CSF. The M-CSF concentration in L929 supernatants was determined via ELISA (R\&D Systems, Minneapolis, MN, United States). The medium was renewed twice per week. Within 2 weeks of cell culture, CD11b+ cells differentiated from separate round shaped cells to a dense network of adherend cells (Supplementary Figure S1).

\section{Stimulation}

After cultivation for 14 days, cells were stimulated for $24 \mathrm{~h}$ in medium with 5\% FCS and $100 \mathrm{ng} / \mathrm{ml}$ LPS (E. coli O111:B4; Sigma Aldrich, Taufkirchen, Germany) or without LPS (control). Non-toxic concentration of LPS $(100 \mathrm{ng} / \mathrm{ml})$ has been titrated previously in vitro via MTT-assay. Similar LPS concentration has been used in other in vitro (Karlstetter et al., 2010, 2011) studies.

\section{Immunofluorescence}

For immunofluorescent analysis the cells $\left(6 \times 10^{4} /\right.$ well $)$ were cultured for 14 days on 8-well glass chamber slides (Merck Millipore). Then, cells were stimulated with/without LPS. After $24 \mathrm{~h}$ cells were fixed in PBS containing 4\% paraformaldehyde (Carl Roth) for $30 \mathrm{~min}$ at room temperature (RT). Cells were air dried, unspecific binding sites were blocked by $5 \%$ goat serum (Biozol, Eching, Germany) in PBS for $1 \mathrm{~h}$ at RT. Cells were permeabilized using permeabilization buffer (Affymetrix, San Diego, CA, United States) in PBS/1\% FCS for $30 \mathrm{~min}$ at RT, and stained using $0.5 \mu \mathrm{g} / \mathrm{ml}$ polyclonal goat anti-mouse/rat Ibal (Abcam, Berlin, Germany) over night at $4^{\circ} \mathrm{C}$. As secondary antibody $1 \mu \mathrm{g} / \mathrm{ml}$ polyclonal donkey anti-goat Alexa Fluor 488 (Abcam) were applied for $1 \mathrm{~h}$ at RT. Finally, nuclei were stained by $1 \mu \mathrm{g} / \mathrm{ml}$ Hoechst 33342 (Sigma Aldrich) and slides were mounted by using Mowiol (Sigma Aldrich). The cellular specimens were examined by immunofluorescence microscopy (ApoTome.2; Zeiss, Oberkochen, Germany) and displayed by ZEN 2.3 lite software (Zeiss).

\section{Cytokine and Chemokine Analysis}

For cytokine analysis, cells were cultured in 6-well plates and were left unstimulated (control) or stimulated with LPS. The $24 \mathrm{~h}$ cell culture supernatants were harvested and analyzed for their cytokine content by ELISA: interleukin-6 (IL-6), tumor necrosis factor alpha (TNF- $\alpha)$, IL-10 - all purchased from Biolegend (Koblenz, Germany) and transforming growth factor beta 1 (TGF- $\beta 1$; ELISA Ready-SET-Go Human/Maus TGF beta 1 , eBioscience/Thermo Fisher, Dreieich, Germany). Reactions were performed in duplicates. Analysis was performed according to the manufacturer's instructions.
For chemokine quantification including CC chemokine ligands (CCL) MCP-1 (CCL2), MIP-1 $\alpha$ (CCL3), MIP$1 \beta$ (CCL4), RANTES (CCL5), Eotaxin (CCL11), TARC (CCL17), MIP-3 $\alpha$ (CCL20), and MDC (CCL22), C-X-C motif chemokine ligands (CXCL) KC (CXCL1), LIX (CXCL5), MIG (CXCL9), IP-10 (CXCL10), BLC (CXCL13), and bead-based multiplex LEGENDplex ${ }^{\mathrm{TM}}$ analysis (LEGENDplex ${ }^{\mathrm{TM}}$ Mouse Proinflammatory Chemokine Panel (13-plex; Biolegend) were used according to the manufacturer's instructions. Reactions were performed in duplicates. Analysis was performed with the Cytoflex flow cytometer (Beckman Coulter, Krefeld, Germany). Data were analyzed via Legendplex V8.0 software (Biolegend) and specified as $\mathrm{pg} / \mathrm{ml}$.

\section{NO-Assay}

Detection of NO was performed indirectly via nitrite in a 96-well flat bottom cell culture plate. $10 \mu \mathrm{M}$ sodium nitrite standard (Sigma-Aldrich, Taufkirchen) was used 1:2 with PBS in a serial dilution series. Supernatants of cell culture were applied undiluted as a triple determination. Negative control (culture medium) was diluted 1:2 with PBS. To each well $50 \mu l$ of sulphanilic acid solution (1\% sulphanilic acid (Sigma-Aldrich, Taufkirchen) in 4N HCL (Carl Roth, Karlsruhe) was added followed by $10 \mu \mathrm{l}$ of concentrated HCL. The plate was incubated at RT for $10 \mathrm{~min}$. $50 \mu \mathrm{l}$ of $\mathrm{N}$-(1-naphthyl) ethylenediamine solution (1\% N-(1-naphthyl) ethylenediamine (Sigma-Aldrich) in methanol (Carl Roth) was added to each well. Intensity of discoloration was proportional to NO content in the sample. Measurement was performed with a wavelength of $550 \mathrm{~nm}$ in the microplate reader and $\mathrm{NO}$ content (in $\mu \mathrm{M}$ ) was determined via linear regression.

\section{Flow Cytometry Analysis}

For M1/2 phenotype classification via flow cytometry, cells were cultured in 6-well plates and were stimulated with LPS or left unstimulated (control). Following marker were used for M1/2 classification: M1 marker: CCR2; CD86; M2 marker: CX3CR1; CD206. For analysis of intracellular cytokines, brefeldin A (eBioscience) as a protein transport inhibitor was added for the last $6 \mathrm{~h}$ of $24 \mathrm{~h}$ stimulation, which promotes accumulation of intracellular cytokines within the cells. After $24 \mathrm{~h}$, cells were harvested using Accutase (Biowest, Nuaillé, France), and prestained with CD16/CD32 Fc-block (93; TruStain fcX, Biolegend). The following antibodies were used for targeting: CD11b (BV510; M1/70), CX3CR1 (APC/Fire 750; SA011F11), CD206 (APC; C068C2), and CD86 (PE/Cy7; GL-1) - all purchased from Biolegend - and CCR2 (AF700; \#475301) purchased from R\&D Systems (Wiesbaden, Germany). Cells were washed twice with PBS and were then analyzed.

For intracellular cytokine staining, cells were fixed with IC fixation buffer (eBioscience), permeabilized with permeabilization buffer (eBioscience), and incubated with one of the following anti-mouse antibodies targeting TNF- $\alpha$ (PE/Cy7; MP6-XT22), IL-6 (APC; MP5-20F3), IL-10 (PE/D 594; JES516E3), and TGF- $\beta 1$ (PerCP/Cy5.5; TW7-16B4) - all purchased from Biolegend. Cells were washed twice with permeabilization buffer and analyzed. To exclude dead cells, cells were stained 
with the fixable viability dye (FVD) eFluor ${ }^{\circledR} 450$ (eBioscience) according to the manufacturer's instructions.

Samples were measured using Gallios ${ }^{\mathrm{TM}}$ 10/3 (Beckman Coulter) equipment. At least 300,000 viable FVD efluor ${ }^{\circledR} 450$ negative and CD11b-positive events per sample were counted using Kaluza 1.0 software. Data were analyzed using Kaluza Analysis 2.1 Software (Beckman Coulter) and the percentage of positive cells was documented.

\section{Statistics}

For statistical analysis, GraphPad PRISM 7.04 software was used. The data obtained were analyzed for normal distribution (Shapiro-Wilk normally test) and for homogeneity of variance (Brown-Forsythe test). For multiple comparisons, a one-way ANOVA was performed. For a two-group comparison, an unpaired $t$-test was performed. Differences were considered as significant at ${ }^{*} p<0.05,{ }^{* *} p<0.01,{ }^{* * *} p<0.001$, and $* * * * p<0.0001$.

\section{RESULTS}

\section{WT and IL-10 KO Iba1+ Cells in vitro}

It is well known that microglia cells express CD11b which was used by Holt et al. for positive MACS selection of brain derived microglia (Holt and Olsen, 2016). We first aimed to characterize the MACS-isolated CD11b-positive brain derived primary cells as microglia, and analyzed their morphological phenotype when left unstimulated (control) and upon pro-inflammatory conditions via LPS stimulation. As CD11b is not a microglia specific marker and other microglia specific marker as P2Y12 are down regulated upon LPS stimulation (Haynes et al., 2006) we used Ibal as microglia related marker which has been widely used for detection of microglia both in vitro and in situ (Ito et al., 1998; Sukhorukova et al., 2012; Boche et al., 2013; Khozhai and Otellin, 2013; Sobin et al., 2013; Caldeira et al., 2014, 2017).

Immunofluorescence staining of $\mathrm{CD} 11 \mathrm{~b}+$ brain derived primary cells of WT and IL-10 KO mice against Ibal showed that the majority of unstimulated and LPS stimulated cells from WT and IL-10 KO mice were positively stained for Iba-1. The mean fluorescence intensity of the Iba1+ staining did not differ between the culture conditions (data not shown). When left untreated Iba1+ cells showed slim cell bodies with elongated dendrites in vitro (Figures 1A,C). After $24 \mathrm{~h}$ stimulation with LPS, most of the Iba1+ cells showed a round cell shape with short cell extensions. This was the case for both WT and IL-10 KO Iba+ cells (Figures 1B,D). With regard to their origin, the isolation protocol, and the marker staining, the MACS sorted CD11b+ brain derived primary Iba $1+$ cells are termed as microglia cells.

\section{LPS Induced Cytokine and Chemokine Patterns of WT and IL-10 KO Microglia} Cytokine analysis via ELISA (Figures 2A-D and Supplementary Table S1) showed that LPS treatment led to significantly elevated secretion of IL- 6 and TNF- $\alpha$ in the supernatants in both WT and IL-10 KO microglia $(p<0.0001)$. While IL-10 KO cells did

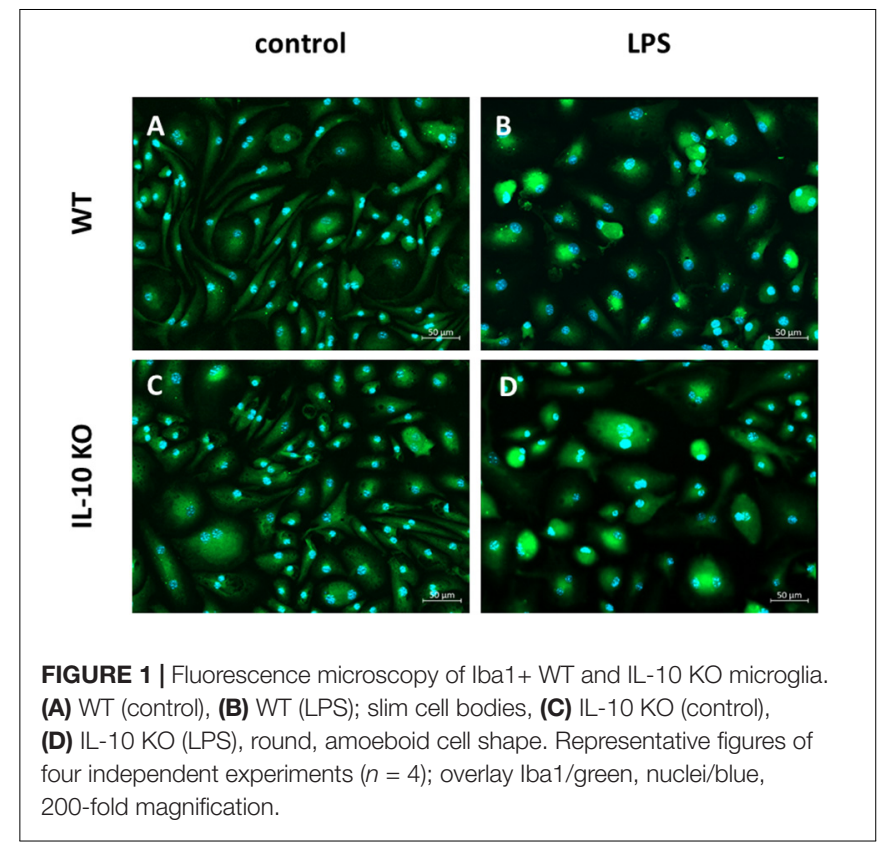

not produce IL-10, WT cells secreted significantly more IL-10 upon LPS treatment than unstimulated cells (control: $40 \pm 17$ pg/ml, LPS: $332 \pm 91 \mathrm{pg} / \mathrm{ml} ; p<0.001)$. Furthermore, IL-10 KO cells secreted a significantly lower amount of TGF- $\beta 1$ upon LPS stimulation than WT cells (IL-10 KO: $68 \pm 27$ pg/ml; WT: $184 \pm 43 \mathrm{pg} / \mathrm{ml} ; p<0.05)$.

Intracellular flow cytometry (Figures $2 \mathrm{E}-\mathbf{H}$ and Supplementary Figure S2) showed that LPS stimulation significantly increased the number of TNF- $\alpha+$ cells in both WT (control: $6 \pm 0.8 \%$, LPS: $28.5 \pm 4.4 \% ; p<0.001$ ) and IL-10 KO (control: $7 \pm 1.9 \%$, LPS: $46.4 \pm 5.7 \%$; $p<0.0001$ ) microglia while the number of IL-6+ cells was only significantly increased in IL-10 KO (control: $2.5 \pm 0.9 \%$, LPS: $18.5 \pm 6.2 \%$; $p<0.001$ ). Intracellular IL-10 staining was negative in IL-10 KO microglia and did not differ between the control and LPS group in WT microglia.

Overall, IL-10 KO microglia showed a significantly higher number of TNF- $\alpha$ - and IL-6-positive cells after LPS stimulation $(p<0.05)$ than WT microglia.

In order to analyze chemokine patterns of WT and IL-10 KO microglia, supernatants of control and LPS-treated cells were analyzed according to their content of CCL and C-X-C motif chemokine ligands (CXCL) via LEGENDplex ${ }^{\mathrm{TM}}$ analysis (Figure 3 and Supplementary Table S1). No differences were found between WT and IL-10 KO microglia cells in the control group (Supplementary Table S1). Compared to WT cells, IL$10 \mathrm{KO}$ microglia showed a significantly enhanced net release ( $\Delta=$ LPS minus control) of the CC family chemokines CCL3 (WT: $142 \pm 26 \mathrm{pg} / \mathrm{ml}$, IL-10 KO: $366 \pm 71 \mathrm{pg} / \mathrm{ml}$ ), CCL4 (WT: $175 \pm 42 \mathrm{pg} / \mathrm{ml}$, IL-10 KO: $494 \pm 107 \mathrm{pg} / \mathrm{ml}$ ), and CCL22 (WT: $133 \pm 20$ pg/ml, IL-10 KO: $375 \pm 80$ pg/ml) (Figures 3B,C,H; $p<0.05$ ). This could also be observed for CXC family chemokines CXCL5 (WT: $163 \pm 29$ pg/ml, IL-10 KO: $425 \pm 98$ pg/ml), CXCL9 (WT: $337 \pm 88$ pg/ml, IL-10 KO: 


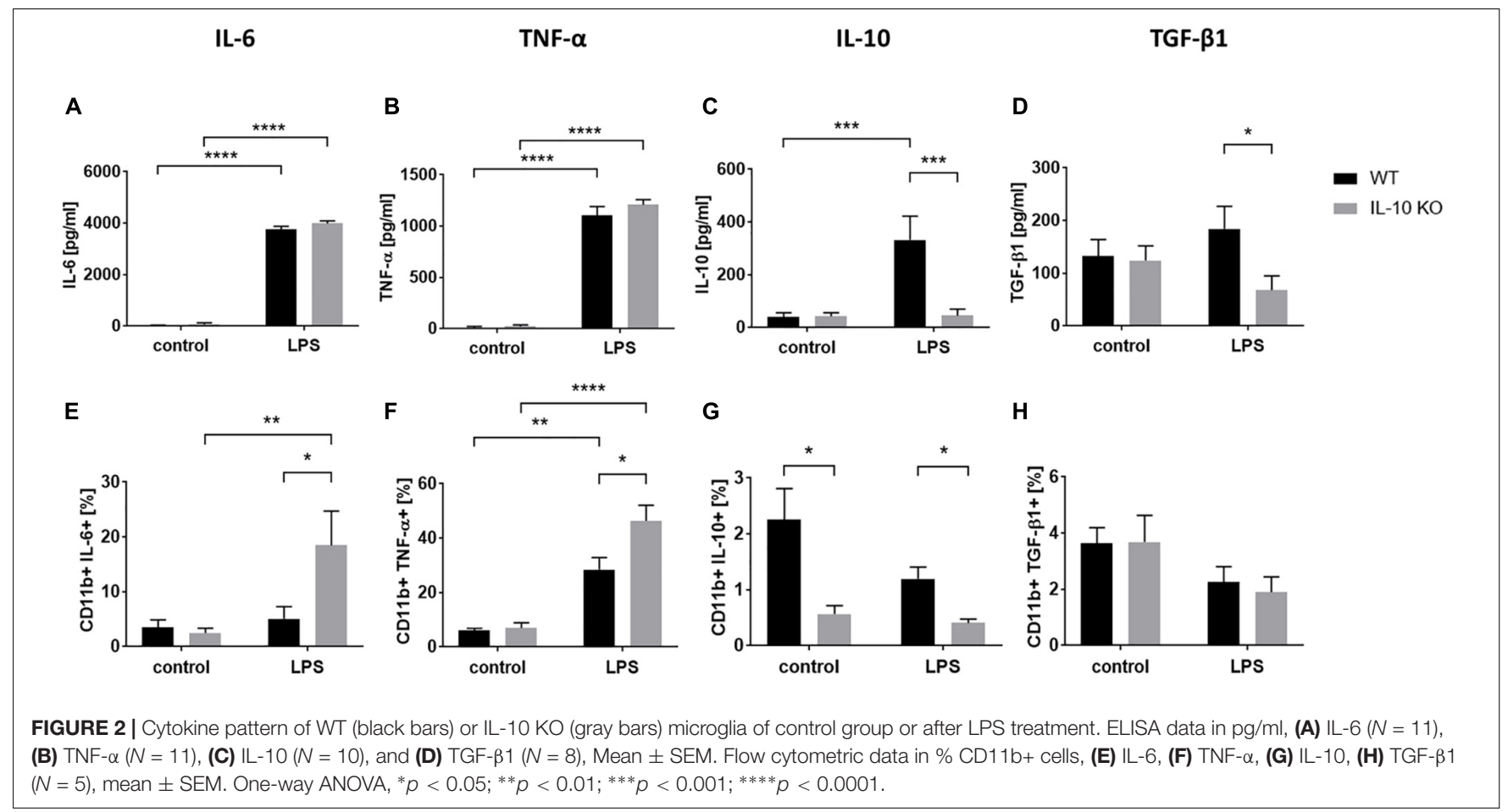

$635 \pm 80 \mathrm{pg} / \mathrm{ml}$ ), CXCL10 (WT: $145 \pm 27 \mathrm{pg} / \mathrm{ml}$, IL-10 KO: $436 \pm 105 \mathrm{pg} / \mathrm{ml}$ ), and CXCL13 (WT: $165 \pm 28 \mathrm{pg} / \mathrm{ml}$, IL-10 KO: $409 \pm 87 \mathrm{pg} / \mathrm{ml}$ ) (Figures 3J-M; $p<0.05$ ).

Analysis of NO level in supernatants showed a significant increase upon LPS stimulation $(p<0.001)$ in supernatants of both, WT and IL-10 KO microglia without significant differences between both genotypes (Supplementary Figure S3).

\section{LPS Promotes M1 Phenotype in IL-10 KO Microglia}

Flow cytometry analyses of WT and IL-10 KO microglia showed that $88.01 \pm 4.29 \%$ of WT and $69.34 \pm 10.5 \%$ of IL-10 KO cells were CD11b+ in medium control. Expression of CD11b did not significantly changed upon LPS treatment to $61.54 \pm 12.8 \%$ in WT and $60.54 \pm 22.6 \%$ in IL-10 KO cells. Besides, no significant differences were detected between both genotypes (Figure $\mathbf{4 A}$ ). Next, we checked the activation status of microglia by flow cytometry analysis, using CCR2 as a common M1 marker (Michelucci et al., 2009) and CX3CR1 as a marker for non-polarized microglia, respectively (Cunha et al., 2016). CCR2 was significantly upregulated after LPS stimulation in both WT (control: $13.4 \pm 3.4 \%$, LPS: $31.7 \pm 8.4 \% ; p<0.05$ ) and IL-10 KO (control: $11.8 \pm 2.8 \%$, LPS: $31.9 \pm 4.1 \%$; $p<0.05$; Figure 4B) microglia without significant differences between the two genotypes. Baseline CX3CR1 expression was significantly higher in IL-10 KO microglia $(42.8 \pm 4 \%)$ than in WT microglia $(29 \pm 0.7 \%$; $p<0.05$; Figure 4C). Upon LPS stimulation CX3CR1 was significantly downregulated in both genotypes (WT: $13 \pm 4.5 \%$, $p<0.05$; IL-10 KO: $8.8 \pm 1.2 \%, p<0.001)$ compared to the control groups.
M1/2 classification of microglia according to their expression of CD86 (M1) and CD206 (M2) (Zhou et al., 2017) showed no differences in the control group (Figures 4D-F). LPS treatment significantly elevated the number of CD86+ CD206- cells (M1 phenotype) in IL-10 KO microglia (control: $9 \pm 4.1 \%$, LPS: $36.9 \pm 14 \%$; $p<0.05$; Figure 4D) while WT cells were unaltered. Both genotypes showed fewer CD86-CD206+ cells (M2 phenotype) after LPS treatment (WT: $43.8 \pm 5.9 \%$; IL-10 KO: LPS: $5.8 \pm 3.4 \%$; Figure 4E; $p<0.05$ ), whereby these cells were significantly reduced in IL-10 KO cells compared to WT cells (Figure 4E; $p<0.05$ ). Analysis of CD86+ CD206+ cells (intermediate M1/2 phenotype) did not show any differences upon LPS stimulation nor any differences related to the genotype, respectively (Figure 4F).

\section{DISCUSSION}

In this study we analyzed the effect of IL-10 deficiency on the M1/2 phenotype of microglia in an inflammatory environment in vitro. Herein, we isolated CD11b-positive cells from the brain of postnatal mice at the age of 2-14 days by using column-based magnetic separation with CD11b microbeads (Holt and Olsen, 2016).

As CD11b is not a microglia specific marker, cells were stained for microglia-related protein ionized calcium-binding adapter molecule 1 (Iba1) and subjected to immunofluorescence microscopy. Ibal as microglia related marker which has been widely used for detection of microglia in vitro and in situ (Ito et al., 1998; Sukhorukova et al., 2012; Boche et al., 2013; Khozhai and Otellin, 2013; Sobin et al., 2013; Caldeira et al., 2014, 2017). Even though, both markers, CD11b and Iba1, are well established 


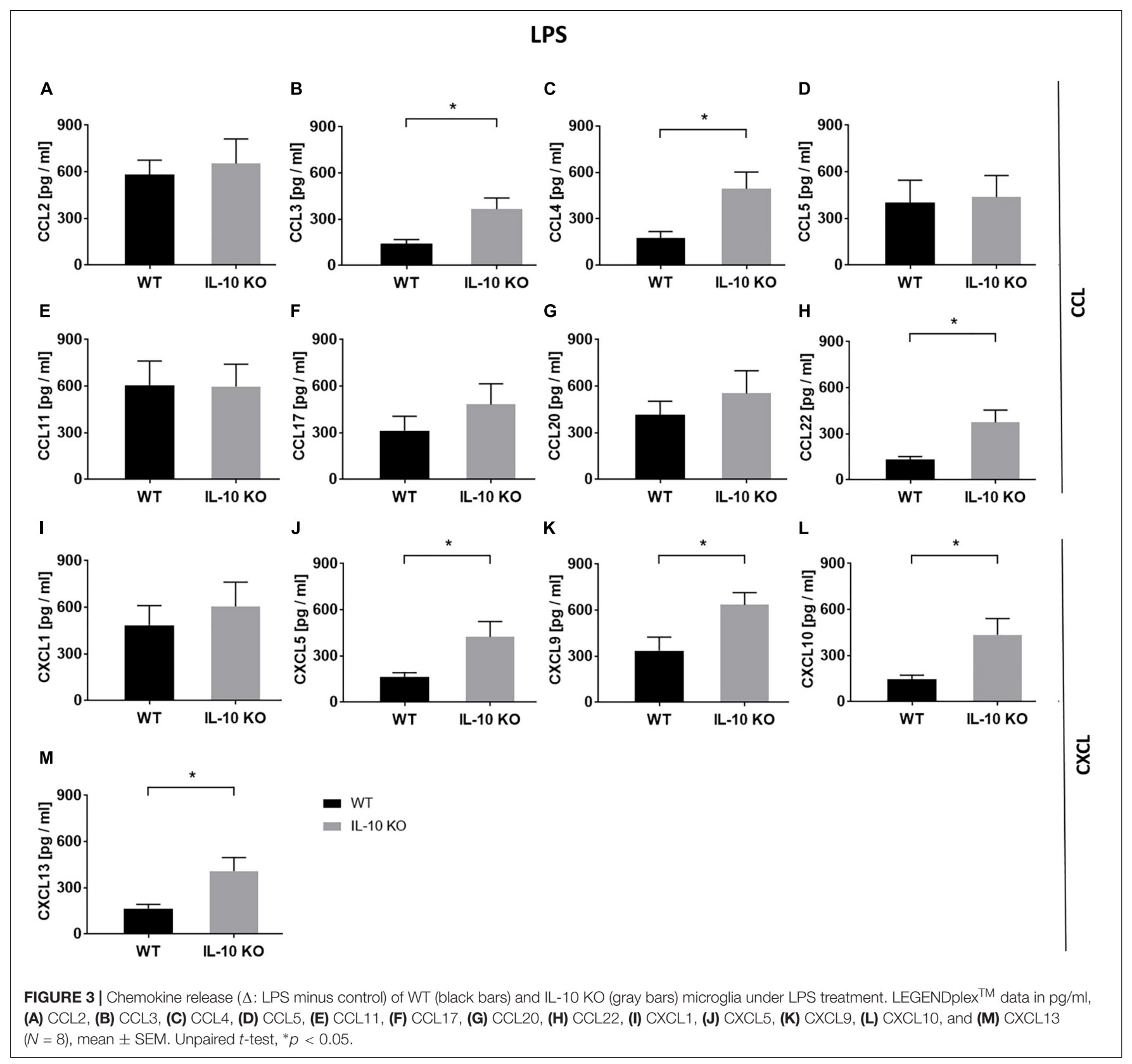

as common microglial markers (Robinson et al., 1986; Ito et al., 1998), they are not unique to microglia. However, other markers for microglia cells have been described e.g., TMEM119 (Bennett et al., 2016), Sall1 (Buttgereit et al., 2016), P2Y12 (Mildner et al., 2017), or Siglec-H (Konishi et al., 2017). But also these markers have drawbacks, as TMEM119 is absent in immature microglia (Satoh et al., 2016), Sall1 is not exclusively expressed by microglia during CNS development (Harrison et al., 2012; Buttgereit et al., 2016; Koso et al., 2018), and P2Y12 shows decreased expression in activated microglia (Haynes et al., 2006; Amadio et al., 2014; Mildner et al., 2017). Whereas the marker Siglec-H seem to be constitutively expressed in microglia indepenedently of their activation state (Konishi et al., 2017) suggesting this is a promising specific microglia marker. However, in the current study CD11b has been used for MACS based isolation of the primary brain derived microglia. As the CD11b expression was still high at time of sampling, we decided to use CD11b as a single pan marker for the gating of viable microglia in flow cytometry analysis. Other markers suitable for flow cytometric analysis of microglia are a combination of at least two markers e.g., CD11b bigh CD45 ${ }^{\text {med }}$ (Martin et al., 2017; Peng et al., 2017) and TEMEM119 ${ }^{+}$Sall1 ${ }^{+}$(Li et al., 2018).

In the current study we used the marker Iba-1 for characterization of microglia. Almost all cells of WT and IL$10 \mathrm{KO}$ mice were positively stained for Iba1. Thus, with respect to the isolation method and origin of the cells we 
A

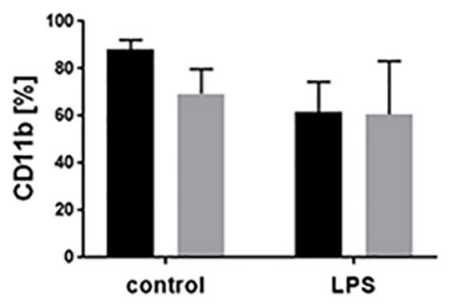

M1

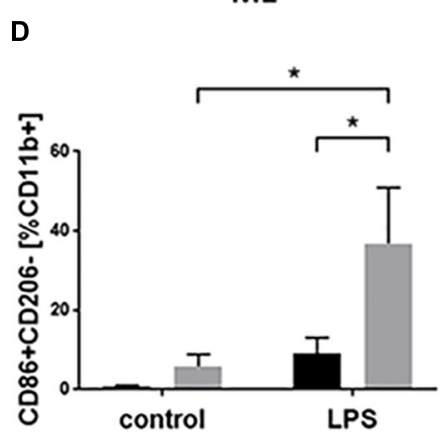

B

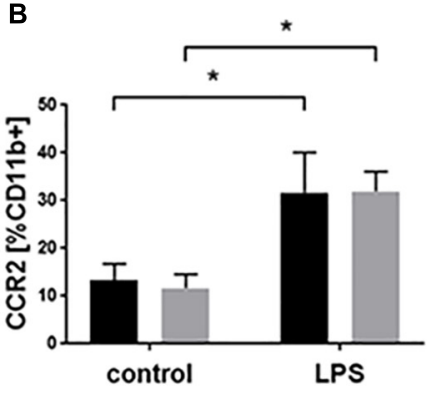

M2

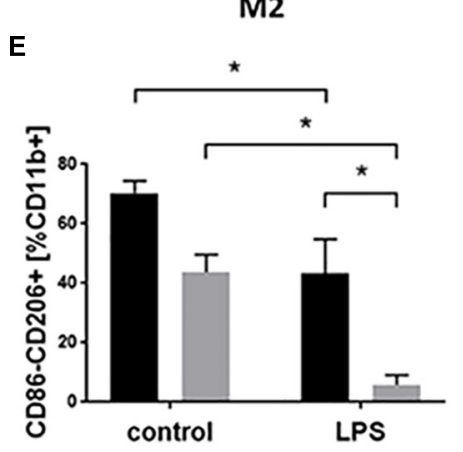

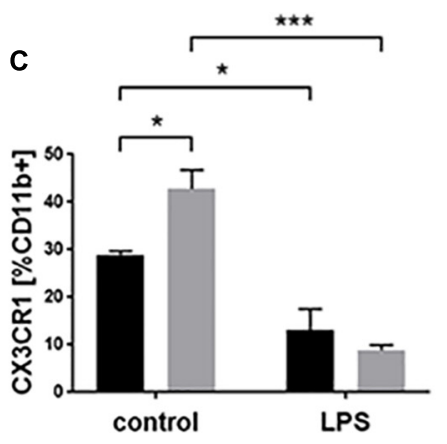

$\mathrm{M} 1 / 2$

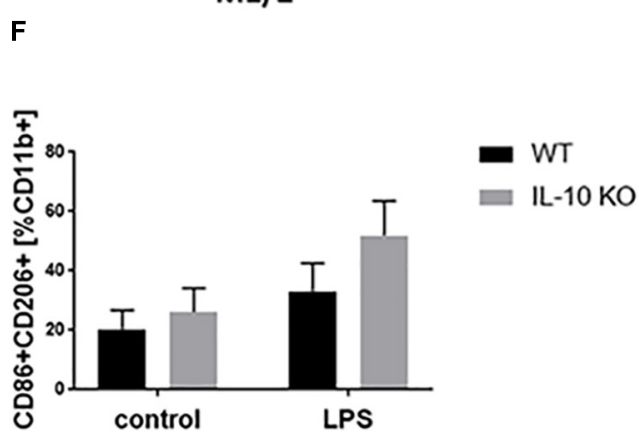

FIGURE 4 | Flow cytometry of WT (black bars) and IL-10 KO (gray bars) microglia of control group or after LPS treatment. Data in\% of CD11b+ cells, (A) CD11b, (B) CCR2, (C) CX3CR1, (D) M1 CD86+ CD206-, (E) M2 CD86-CD206+, (F) M1/2 CD86+ CD206+ (N = 3), mean \pm SEM. One-way ANOVA, * $p$ < 0.05; $* * * p<0.001$

assume that these cells are brain derived microglia. Microglia were stimulated with LPS, which has been widely used to activate microglia both in vitro and in vivo (Becher and Antel, 1996; Nadeau and Rivest, 2000; Karlstetter et al., 2010, 2011). However, it has been previously shown that cultured microglia do not display the same dramatic change in morphology when activated (Kettenmann, 2006) as they do in vivo, where highly ramified microglia transform into amoeboid-phagocytic microglia (Hellwig et al., 2013; Torres-Platas et al., 2014). Thus, in the control group, the Ibal+ cells classified as microglia had long and slender cell bodies and showed a round-shaped amoeboid form upon LPS stimulation. These are the common morphological changes of microglia observed in vitro upon LPS stimulation (abd-el-Basset and Fedoroff, 1995). We did not perform further morphological analysis (e.g., ramification index, branches, spines soma diameter) (Jonas et al., 2012; Kozlowski and Weimer, 2012; Davis et al., 2017; Luckoff et al., 2017) in our cell culture model to evaluate morphological differences between WT and IL-10 KO microglia in vitro. However, it seems that lack of IL-10 did not influence the morphology of microglia dramatically when left untreated nor upon LPS treatment in vitro. Whereas, morphological analysis of spinal cord microglia in situ of LPS treated WT and IL-10 KO mice showed morphological differences in IL-10 KO mice (Anderson et al., 2017).

In order to examine the impact of IL-10 on the M1/2 phenotype of WT and IL-10 KO microglia, the cytokine and chemokine patterns of microglia upon LPS treatment were analyzed. According to their M1 or M2 phenotype activated microglia can exert different effector functions (Michelucci et al., 2009), and be either neurotoxic and generate a massive inflammatory response (M1 phenotype), releasing cytokines such as TNF- $\alpha$ and IL-6 (Magni et al., 2012), or dampen inflammation (M2 phenotype) by secreting anti-inflammatory mediators, including IL-10 and TGF- $\beta$ (Suh et al., 2013; Tang and Le, 2016). At least it has to be assumed that the microglia phenotype is highly transitional and modulated in dependence on their environment (Goldmann and Prinz, 2013). Thus, we could show that both WT and IL-10 KO microglia express as well pro-inflammatory (IL-6, TNF- $\alpha, \mathrm{NO}$ ) and anti-inflammatory (WT: IL-10, TGF- $\beta$; IL-10 KO: TGF- $\beta$ ) cytokines pointing to a transitional phenotype including both M1 and M2 phenotype.

We could show that microglial activation by LPS enhanced secretion of IL- 6 and TNF- $\alpha$ in WT and IL-10 KO cells. It is known that IL-10 downregulates the LPS-induced production of several proinflammatory cytokines (Frei et al., 1994; Lodge and Sriram, 1996). Elevated LPS induced IL-6 and TNF- $\alpha$ expression could be shown in brain tissue of IL-10 KO mice compared to WT mice via qPCR (Anderson et al., 2017). Therefore, we expected a higher amount of pro-inflammatory cytokine IL- 6 and TNF- $\alpha$ in the supernatants of IL-10 KO microglia, but found no differences between WT and IL-10 KO cells. First, we assumed a saturation effect which make any differences undetectable via ELISA. Whereas, the flow-cytometric analysis showed that 
genetic depletion of IL-10 increased the frequency of IL-6+ and TNF- $\alpha+$ cells after LPS stimulation. Which implies, that lack of IL-10 leads to an enhanced IL- 6 and TNF- $\alpha$ expression upon LPS treatment.

When considering both, the similar cytokine content in both genotypes and the lower frequency of TNF- $\alpha+$ and IL- $6+$ of WT cells, a higher cytokine release by WT cells upon LPS treatment could be also responsible for the similar cytokine content in the supernatant.

It has been previously shown that TGF- $\beta 1$ plays a central role in microglial development and homeostasis both in vitro and in vivo (Butovsky et al., 2014). TGF- $\beta 1$ is important in the microglial transition from a proinflammatory to a reparative M2 phenotype, by reducing microglial IL-6 secretion (Taylor et al., 2017). In an LPS-treated mixed culture of astrocytes and microglia, by microglia released IL-10 reduced the secretion of IL-1 $\beta$, IL- 6 and TNF- $\alpha$ (Ledeboer et al., 2000) and increased the release of TGF- $\beta 1$ by astrocytes, which in turn attenuated the LPS-induced activation of microglia (Norden et al., 2014). In our study, IL-10 and TGF- $\beta 1$ was upregulated in WT microglia after LPS stimulation, while IL-10 KO cells were negative for IL-10 and released significantly less TGF- $\beta 1$. As TGF-b1 is important for the microglia homeostasis (Spittau et al., 2013), silencing of TGFb2R lead to an activated microglial phenotype and might prone the cells rather to a pro-inflammatory than an anti-inflammatory state (Zoller et al., 2018). Thus, IL-10 depletion in microglia cells might result in lower TGF- $\beta 1$ release and thereby participate in regulating M2 cell frequency by influencing TGF- $\beta 1$.

Microglia have been further shown to be potential sources of chemokines during CNS inflammation (Hesselgesser and Horuk, 1999) and that they upregulate chemokines at disease onset in EAE (Yamasaki et al., 2014). Chemokines represent a superfamily of small peptides, which act as chemoattractants to guide migration of other immune cells. Chemokines of the CXC (IP-10) and of the CC-family (MIP- $1 \alpha$, MIP- $1 \beta$, MCP-1, RANTES) have been shown to be produced by microglia and may therefore contribute to the intracerebral recruitment of $\mathrm{T}$ cells, macrophages, and dendritic cells to the inflamed tissue (Aloisi, 2001). Previous studies showed an increased CCL2 secretion by primary microglia and astrocytes upon LPS stimulation in vitro (Hayashi et al., 1995), and in vivo thus mediating the migration of microglia, monocytes and lymphocytes to the sites of inflammation in the CNS (Gunn et al., 1997; Babcock et al., 2003). We confirmed the enhanced CCL2 release upon LPS stimulation in WT and IL-10 KO microglia, but could not show any impact of lacking IL-10 on the CCL2 release as shown for TGF- $\beta$ R2 KO microglia in vitro where CCL2 was found to be enhanced secreted upon LPS treatment (Zoller et al., 2018).

In our study, LPS stimulation led to a significantly elevated release of chemokines of both the CC family CCL3 (MIP-1 $1 \alpha$ ), CCL4 (MIP-1 $\beta$ ), and CCL22 (MDC) and the CXC family CXCL5 (LIX), CXCL9 (MIG), CXCL10 (IP-10), and CXCL13 (BLC) in IL-10 KO microglia compared to WT microglia. CCL3 and CCL4 are both members of the group of macrophage inflammatory proteins (MIP), which are important for inflammatory responses. It has been shown that they induce the synthesis and release of the proinflammatory cytokines IL-1, IL-6, and TNF- $\alpha$ from fibroblasts and macrophages (Irving et al., 1990; Ren et al., 2010). Moreover, microglia produce chemokines, for example, MDC, chemotactic for dendritic cells and differentiated $\mathrm{T}$ cells during EAE or after in vitro exposure to IFN- $\gamma$ (Aloisi, 2001). Thus, an enhanced release of chemokines by microglia in proinflammatory environment might support the development of a more severe $\mathrm{EAE}$ and an accelerated disease progression in IL-10 KO mice (Bettelli et al., 1998; Samoilova et al., 1998; Anderson et al., 2004; Zhang et al., 2004). With regard to the improvement of therapeutic strategies it might be more effective to change the M1 or M2 phenotype of resident microglia, than to influence the peripheral immune response via systemic drugs. It has been already shown that M2 polarization of macrophages or microglia is a promising treatment option in EAE (Butovsky et al., 2006; Mikita et al., 2011; Cao and He, 2013; McMurran et al., 2016). Favoring M2 generation or respective modulation of microglia might have beneficial effects in chronic diseases as shown for IL-10 in the EAE model (Yang et al., 2009). Furthermore, modulation of retinal microglia via specific ligands (e.g., TSPO, minocycline) has been shown to be beneficial for the outcome of retinal degenerative diseases (Akhtar-Schafer et al., 2018).

The differential M1 or M2 activation states of microglia coexist in inflamed tissues during the development of neurodegenerative diseases and can mediate cell damage or neuroprotective effects. M1 cells can induce tissue damage, demyelination, and neuronal death in the CNS in the EAE model (Almolda et al., 2011; Liu et al., 2013; Jiang et al., 2014), whereas M2 cells are known to be involved in suppressing EAE (Jiang et al., 2014) and in resolving inflammation and repairing tissue (Laria et al., 2016).

IL-10 may counteract an immune response toward an M1 phenotype and modulate the polarization of microglial cells to a more anti-inflammatory M2 phenotype, likewise, to control neuroinflammation.

To further analyze the microglia phenotype we used the surface marker CCR2 as M1 marker (Michelucci et al., 2009) and CX3CR1 as a marker for non-polarized microglia, respectively (Cunha et al., 2016). Previous studies showed an increased CCL2 secretion and/or CCR2 expression in vitro and in vivo during pro-inflammatory conditions (Hayashi et al., 1995; Berman et al., 1996; Gunn et al., 1997; Babcock et al., 2003; Glabinski et al., 2003). Our results confirmed the increased CCL2 and CCR2 expression upon LPS stimulation in WT and IL-10 KO cells without significant difference between both genotypes.

We further studied the fractalkine receptor CX3CR1, which is highly expressed in the non-polarized M0 microglial phenotype (Sheridan and Murphy, 2013). As previously shown for N9 microglial cells (Cunha et al., 2016), we showed that CX3CR1 was significantly downregulated after LPS stimulation in both WT and IL-10 KO microglia.

Lively et al. describe a IL-10 mediated down regulation of CXCR1 expression in murine primary microglia (Lively et al., 2018). We can confirm this finding as the frequency of CX3CR1+ microglia was higher in unstimulated IL-10 KO microglia than in WT microglia, indicating a suppressive effect of IL-10 on CX3CR1 expression. 
Classification via the marker CCR2 and CX3CR1 used for macrophages did not show differences in the two genotypes uponLPS treatment. We therefore include further M1 (CD86) and M2 (CD206) marker which were used for M1/2 phenotyping of microglia cells (Peng et al., 2017; Zhou et al., 2017). Here, our analysis showed a reduced M2 CD86-CD206+ phenotype and an unaltered M1/2 CD86+ CD206+ phenotype in both genotypes upon LPS treatment. However, the M2 phenotype was significantly reduced in IL-10 KO compared to WT microglia after LPS stimulation. Furthermore, an LPS-induced M1 CD86+ CD206- phenotype could be shown in IL-10 KO cells, but not in WT cells.

Taken together, our results suggest that IL-10 deficiency did not have a significant effect on microglia M1/2 phenotype when left untreated. Whereas lack of IL-10 promotes microglia to an increased expression of pro-inflammatory cytokines/chemokines and the lower release of TGF- $\beta 1$ as anti-inflammatory cytokine. Thus, these results indicate that absence of IL-10 led to a M1prone microglial phenotype during LPS treatment.

\section{DATA AVAILABILITY STATENMENT}

The datasets generated for this study are available on request to the corresponding author.

\section{ETHICS STATEMENT}

The animal experiments were performed in accordance with the European Health Law of the Federation of Laboratory Animal Science Associations (FELASA) and regulations of the Society for Laboratory Animal Science (GV-SOLAS) in Germany. The protocol was approved by the North Rhine-Westphalia State Agency for Nature, Environment, and Consumer Protection (LANUV) (authorization number AZ 2015.A011/\$4.16.006). All experimental procedures conformed to the guidelines of the National Institutes of Health and to the Association for Research in Vision and Ophthalmology resolution on the use of animals in research.

\section{REFERENCES}

abd-el-Basset, E., and Fedoroff, S. (1995). Effect of bacterial wall lipopolysaccharide (LPS) on morphology, motility, and cytoskeletal organization of microglia in cultures. J. Neurosci. Res. 41, 222-237. doi: 10.1002/jnr.490410210

Akhtar-Schafer, I., Wang, L., Krohne, T. U., Xu, H., and Langmann, T. (2018). Modulation of three key innate immune pathways for the most common retinal degenerative diseases. EMBO Mol. Med. 10:e8259. doi: 10.15252/emmm. 201708259

Almolda, B., Gonzalez, B., and Castellano, B. (2011). Antigen presentation in EAE: role of microglia, macrophages and dendritic cells. Front. Biosci. 16:1157-1171. doi: $10.2741 / 3781$

Aloisi, F. (2001). Immune function of microglia. Glia 36, 165-179. doi: 10.1002/ glia.1106

Aloisi, F., De Simone, R., Columba-Cabezas, S., and Levi, G. (1999). Opposite effects of interferon-gamma and prostaglandin E2 on tumor necrosis factor and interleukin-10 production in microglia: a regulatory loop controlling microglia

\section{AUTHOR CONTRIBUTIONS}

BL, MK, DB, ST, GM, TL, and AH designed the study and wrote the manuscript. BL, DB, SW, MB, TJ, and MK performed the experiments and analyzed the data. All authors read and approved the final version of the manuscript.

\section{FUNDING}

This study was funded by the DFG He 1877/19-1; part of the FOR 2240 program (Lymph) Angiogenesis and cellular immunity in inflammatory diseases of the eye/project 8 uveitis.

\section{ACKNOWLEDGMENTS}

We thank Bo Wang and Kevin Gilhaus for their technical assistance in this study.

\section{SUPPLEMENTARY MATERIAL}

The Supplementary Material for this article can be found online at: https://www.frontiersin.org/articles/10.3389/fncel. 2019.00430/full\#supplementary-material

FIGURE S1 | Isolated CD11b+ cells cultured in 8-well chamber slides develop from (A) round shaped cells at day 1 to cells with growing cell extension at (B) day 4, (C) day 7, and (D) after 12 days in cell culture to a dense network of cells (Magnification $\times 200$ ).

FIGURE S2 | Gating Strategy for primary microglia in flow cytometry. (A) Microglia in SSC/FSC profile, (B) microglia stained with the live-dead dye eFluor450. Living cells (FVD eFlour450 negative) are shown in region 1 (R1), (C) isotpye control IgG2b к BV510 and IgG1 к APC, (D) CD11b+ BV510 cells with IgG1 к APC Isotype control, and (E) intracellular cytokine staining of CD11b+ cells with anti-IL-6 APC.

FIGURE S3 | NO release of WT (black bars) or IL-10 KO (gray bars) microglia of control group or after LPS treatment. NO content in $\mu \mathrm{M}(N=12)$ in the supernatant of microglia. Mean \pm SEM. One-way ANOVA. ${ }^{* * * *} p<0.0001$.

TABLE S1 | Cytokine/Chemokine level.

pro- and anti-inflammatory activities. J. Neurosci. Res. 56, 571-580. doi: 10 1002/(sici)1097-4547(19990615)56:6<571::aid-jnr3>3.3.co;2-g

Amadio, S., Parisi, C., Montilli, C., Carrubba, A. S., Apolloni, S., and Volonte, C. (2014). P2Y(12) receptor on the verge of a neuroinflammatory breakdown. Mediators Inflamm. 2014:975849. doi: 10.1155/2014/975849

Anderson, A. C., Reddy, J., Nazareno, R., Sobel, R. A., Nicholson, L. B., and Kuchroo, V. K. (2004). IL-10 plays an important role in the homeostatic regulation of the autoreactive repertoire in naive mice. J. Immunol. 173, 828834. doi: 10.4049/jimmunol.173.2.828

Anderson, W. D., Greenhalgh, A. D., Takwale, A., David, S., and Vadigepalli, R. (2017). Novel INfluences of IL-10 on CNS inflammation revealed by integrated analyses of cytokine networks and microglial morphology. Front. Cell Neurosci. 11:233. doi: 10.3389/fncel.2017.00233

Babcock, A. A., Kuziel, W. A., Rivest, S., and Owens, T. (2003). Chemokine expression by glial cells directs leukocytes to sites of axonal injury in the CNS. J. Neurosci. 23, 7922-7930. doi: 10.1523/jneurosci.23-21-07922. 2003 
Balasingam, V., and Yong, V. W. (1996). Attenuation of astroglial reactivity by interleukin-10. J. Neurosci. 16, 2945-2955. doi: 10.1523/JNEUROSCI.16-0902945.1996

Becher, B., and Antel, J. P. (1996). Comparison of phenotypic and functional properties of immediately ex vivo and cultured human adult microglia. Glia 18, 1-10. doi: 10.1002/(sici)1098-1136(199609)18:1<1::aid-glia1>3.3.co;2-i

Bennett, M. L., Bennett, F. C., Liddelow, S. A., Ajami, B., Zamanian, J. L., Fernhoff, N. B., et al. (2016). New tools for studying microglia in the mouse and human CNS. Proc. Natl. Acad. Sci. U.S.A. 113, E1738-E1746. doi: 10.1073/pnas. 1525528113

Berman, J. W., Guida, M. P., Warren, J., Amat, J., and Brosnan, C. F. (1996). Localization of monocyte chemoattractant peptide- 1 expression in the central nervous system in experimental autoimmune encephalomyelitis and trauma in the rat. J. Immunol. 156, 3017-3023.

Bettelli, E., Das, M. P., Howard, E. D., Weiner, H. L., Sobel, R. A., and Kuchroo, V. K. (1998). IL-10 is critical in the regulation of autoimmune encephalomyelitis as demonstrated by studies of IL-10- and IL-4-deficient and transgenic mice. J. Immunol. 161, 3299-3306.

Boche, D., Perry, V. H., and Nicoll, J. A. (2013). Review: activation patterns of microglia and their identification in the human brain. Neuropathol. Appl. Neurobiol. 39, 3-18. doi: 10.1111/nan.12011

Branchi, I., Alboni, S., and Maggi, L. (2014). The role of microglia in mediating the effect of the environment in brain plasticity and behavior. Front. Cell Neurosci. 8:390. doi: 10.3389/fncel.2014.00390

Butovsky, O., Jedrychowski, M. P., Moore, C. S., Cialic, R., Lanser, A. J., Gabriely, G., et al. (2014). Identification of a unique TGF-beta-dependent molecular and functional signature in microglia. Nat. Neurosci. 17, 131-143. doi: 10.1038/nn. 3599

Butovsky, O., Landa, G., Kunis, G., Ziv, Y., Avidan, H., Greenberg, N., et al. (2006). Induction and blockage of oligodendrogenesis by differently activated microglia in an animal model of multiple sclerosis. J. Clin. Invest. 116, 905-915. doi: 10.1172/JCI26836

Buttgereit, A., Lelios, I., Yu, X., Vrohlings, M., Krakoski, N. R., Gautier, E. L., et al. (2016). Sall1 is a transcriptional regulator defining microglia identity and function. Nat. Immunol. 17, 1397-1406. doi: 10.1038/ni.3585

Caldeira, C., Cunha, C., Vaz, A. R., Falcao, A. S., Barateiro, A., Seixas, E., et al. (2017). Key aging-associated alterations in primary microglia response to betaamyloid stimulation. Front. Aging Neurosci. 9:277. doi: 10.3389/fnagi.2017. 00277

Caldeira, C., Oliveira, A. F., Cunha, C., Vaz, A. R., Falcao, A. S., Fernandes, A., et al. (2014). Microglia change from a reactive to an age-like phenotype with the time in culture. Front. Cell Neurosci .8:152. doi: 10.3389/fncel.2014. 00152

Cao, L., and He, C. (2013). Polarization of macrophages and microglia in inflammatory demyelination. Neurosci. Bull. 29, 189-198. doi: 10.1007/s12264013-13240

Chhor, V., Le Charpentier, T., Lebon, S., Ore, M. V., Celador, I. L., Josserand, J., et al. (2013). Characterization of phenotype markers and neuronotoxic potential of polarised primary microglia in vitro. Brain Behav. Immun. 32, 70-85. doi: 10.1016/j.bbi.2013.02.005

Cianciulli, A., Dragone, T., Calvello, R., Porro, C., Trotta, T., Lofrumento, D. D., et al. (2015). IL-10 plays a pivotal role in anti-inflammatory effects of resveratrol in activated microglia cells. Int. Immunopharmacol. 24, 369-376. doi: 10.1016/ j.intimp.2014.12.035

Cua, D. J., Groux, H., Hinton, D. R., Stohlman, S. A., and Coffman, R. L. (1999). Transgenic interleukin 10 prevents induction of experimental autoimmune encephalomyelitis. J, Exp. Med. 189, 1005-1010. doi: 10.1084/jem.189.6.1005

Cunha, C., Gomes, C., Vaz, A. R., and Brites, D. (2016). Exploring new inflammatory biomarkers and pathways during LPS-Induced M1 Polarization. Mediators Inflamm. 2016:6986175. doi: 10.1155/2016/698 6175

Davalos, D., Grutzendler, J., Yang, G., Kim, J. V., Zuo, Y., Jung, S., et al. (2005). ATP mediates rapid microglial response to local brain injury in vivo. Nat. Neurosci. 8, 752-758. doi: 10.1038/nn1472

Davis, B. M., Salinas-Navarro, M., Cordeiro, M. F., Moons, L., and De Groef, L. (2017). Characterizing microglia activation: a spatial statistics approach to maximize information extraction. Sci. Rep. 7:1576. doi: 10.1038/s41598-017017478
Devarajan, G., Chen, M., Muckersie, E., and Xu, H. (2014). Culture and characterization of microglia from the adult murine retina. Sci. World J. 2014:894368. doi: 10.1155/2014/894368

Du, L., Zhang, Y., Chen, Y., Zhu, J., Yang, Y., and Zhang, H. L. (2017). Role of microglia in neurological disorders and their potentials as a therapeutic target. Mol. Neurobiol. 54, 7567-7584. doi: 10.1007/s12035-016-02450

Durafourt, B. A., Moore, C. S., Zammit, D. A., Johnson, T. A., Zaguia, F., Guiot, M. C., et al. (2012). Comparison of polarization properties of human adult microglia and blood-derived macrophages. Glia 60, 717-727. doi: 10.1002/glia. 22298

Fernandes, A., Miller-Fleming, L., and Pais, T. F. (2014). Microglia and inflammation: conspiracy, controversy or control? Cell. Mol. Life Sci. 71, 39693985. doi: 10.1007/s00018-014-16708

Franco, R., and Fernandez-Suarez, D. (2015). Alternatively activated microglia and macrophages in the central nervous system. Prog. Neurobiol. 131, 65-86. doi: 10.1016/j.pneurobio.2015.05.003

Frei, K., Lins, H., Schwerdel, C., and Fontana, A. (1994). Antigen presentation in the central nervous system. The inhibitory effect of IL-10 on MHC class II expression and production of cytokines depends on the inducing signals and the type of cell analyzed. J. Immunol. 152, 2720-2728.

Glabinski, A. R., Bielecki, B., and Ransohoff, R. M. (2003). Chemokine upregulation follows cytokine expression in chronic relapsing experimental autoimmune encephalomyelitis. Scand. J. Immunol. 58, 81-88. doi: 10.1046/j.1365-3083. 2003.01285.x

Goldmann, T., and Prinz, M. (2013). Role of microglia in CNS autoimmunity. Clin. Dev. Immunol. 2013:208093. doi: 10.1155/2013/208093

Gordon, S. (2003). Alternative activation of macrophages. Nat. Rev. Immunol. 3, 23-35. doi: 10.1038/nri978

Gunn, M. D., Nelken, N. A., Liao, X., and Williams, L. T. (1997). Monocyte chemoattractant protein-1 is sufficient for the chemotaxis of monocytes and lymphocytes in transgenic mice but requires an additional stimulus for inflammatory activation. J. Immunol. 158, 376-383.

Hanisch, U. K. (2002). Microglia as a source and target of cytokines. Glia 40, 140-155. doi: 10.1002/glia.10161

Hanisch, U. K. (2013). Functional diversity of microglia - how heterogeneous are they to begin with? Front. Cell Neurosci. 7:65. doi: 10.3389/fncel.2013.00065

Harrison, S. J., Nishinakamura, R., Jones, K. R., and Monaghan, A. P. (2012). Sall1 regulates cortical neurogenesis and laminar fate specification in mice: implications for neural abnormalities in townes-brocks syndrome. Dis. Model Mech. 5, 351-365. doi: 10.1242/dmm.002873

Hayashi, M., Luo, Y., Laning, J., Strieter, R. M., and Dorf, M. E. (1995) Production and function of monocyte chemoattractant protein-1 and other beta-chemokines in murine glial cells. J. Neuroimmunol. 60, 143-150. doi: 10.1016/0165-5728(95)00064-9

Haynes, S. E., Hollopeter, G., Yang, G., Kurpius, D., Dailey, M. E., Gan, W. B., et al. (2006). The P2Y12 receptor regulates microglial activation by extracellular nucleotides. Nat. Neurosci. 9, 1512-1519. doi: 10.1038/nn1805

Hellwig, S., Heinrich, A., and Biber, K. (2013). The brain's best friend: microglial neurotoxicity revisited. Front. Cell Neurosci. 7:71. doi: 10.3389/fncel.2013. 00071

Hesselgesser, J., and Horuk, R. (1999). Chemokine and chemokine receptor expression in the central nervous system. J. Neurovirol. 5, 13-26. doi: 10.3109/ 13550289909029741

Holt, L. M., and Olsen, M. L. (2016). Novel applications of magnetic cell sorting to analyze cell-type specific gene and protein expression in the central nervous system. PLoS One 11:e0150290. doi: 10.1371/journal.pone.0150290

Irving, S. G., Zipfel, P. F., Balke, J., McBride, O. W., Morton, C. C., Burd, P. R., et al. (1990). Two inflammatory mediator cytokine genes are closely linked and variably amplified on chromosome 17q. Nucleic Acids Res. 18, 3261-3270. doi: 10.1093/nar/18.11.3261

Ito, D., Imai, Y., Ohsawa, K., Nakajima, K., Fukuuchi, Y., and Kohsaka, S. (1998). Microglia-specific localisation of a novel calcium binding protein. Iba1. Brain Res. Mol. Brain Res. 57, 1-9. doi: 10.1016/S0169-328X(98)00040-40

Jiang, Z., Jiang, J. X., and Zhang, G. X. (2014). Macrophages: a double-edged sword in experimental autoimmune encephalomyelitis. Immunol. Lett. 160, 17-22. doi: 10.1016/j.imlet.2014.03.006

Jonas, R. A., Yuan, T. F., Liang, Y. X., Jonas, J. B., Tay, D. K., and Ellis-Behnke, R. G. (2012). The spider effect: morphological and orienting classification of 
microglia in response to stimuli in vivo. PLoS One 7:e30763. doi: 10.1371/ journal.pone.0030763

Kalkman, H. O., and Feuerbach, D. (2016). Antidepressant therapies inhibit inflammation and microglial M1-polarization. Pharmacol. Ther. 163, 82-93. doi: $10.1016 /$ j.pharmthera.2016.04.001

Karlstetter, M., Lippe, E., Walczak, Y., Moehle, C., Aslanidis, A., Mirza, M., et al. (2011). Curcumin is a potent modulator of microglial gene expression and migration. J. Neuroinflamm. 8:125. doi: 10.1186/1742-2094-8-125

Karlstetter, M., Walczak, Y., Weigelt, K., Ebert, S., Van den Brulle, J., Schwer, H., et al. (2010). The novel activated microglia/macrophage WAP domain protein, AMWAP, acts as a counter-regulator of proinflammatory response. J. Immunol. 185, 3379-3390. doi: 10.4049/jimmunol.0903300

Kettenmann, H. (2006). Triggering the brain's pathology sensor. Nat. Neurosci. 9, 1463-1464. doi: 10.1038/nn1206- 1463

Khozhai, L. I., and Otellin, V. A. (2013). Reactive microglial changes in rat neocortex and hippocampus after exposure to acute perinatal hypoxia. Morfologiia 143, 23-27.

Kierdorf, K., Erny, D., Goldmann, T., Sander, V., Schulz, C., Perdiguero, E. G., et al. (2013). Microglia emerge from erythromyeloid precursors via Pu.1- and Irf8-dependent pathways. Nat. Neurosci. 16, 273-280. doi: 10.1038/nn.3318

Konishi, H., Kobayashi, M., Kunisawa, T., Imai, K., Sayo, A., Malissen, B., et al. (2017). Siglec-H is a microglia-specific marker that discriminates microglia from CNS-associated macrophages and CNS-infiltrating monocytes. Glia 65, 1927-1943. doi: 10.1002/glia.23204

Koso, H., Nishinakamura, R., and Watanabe, S. (2018). Sall1 regulates microglial morphology cell autonomously in the developing retina. Adv. Exp. Med. Biol. 1074, 209-215. doi: 10.1007/978-3-319-75402-4_26

Kozlowski, C., and Weimer, R. M. (2012). An automated method to quantify microglia morphology and application to monitor activation state longitudinally in vivo. PLoS One 7:e31814. doi: 10.1371/journal.pone.0031814

Kreutzberg, G. W. (1996). Microglia: a sensor for pathological events in the CNS. Trends Neurosci. 19, 312-318. doi: 10.1016/0166-2236(96)10049-7

Kuhn, R., Lohler, J., Rennick, D., Rajewsky, K., and Muller, W. (1993). Interleukin10-deficient mice develop chronic enterocolitis. Cell 75, 263-274. doi: 10.1016/ 0092-8674(93)80068-p

Kumar, A., Alvarez-Croda, D. M., Stoica, B. A., Faden, A. I., and Loane, D. J. (2016). Microglial/Macrophage polarization dynamics following traumatic brain injury. J. Neurotrauma. 33, 1732-1750. doi: 10.1089/neu.2015.4268

Laria, A., Lurati, A., Marrazza, M., Mazzocchi, D., Re, K. A., and Scarpellini, M. (2016). The macrophages in rheumatic diseases. J. Inflamm. Res. 9, 1-11. doi: $10.2147 /$ JIR.S82320

Ledeboer, A., Breve, J. J., Poole, S., Tilders, F. J., and Van Dam, A. M. (2000). Interleukin-10, interleukin-4, and transforming growth factorbeta differentially regulate lipopolysaccharide-induced production of proinflammatory cytokines and nitric oxide in co-cultures of rat astroglial and microglial cells. Glia 30, 134-142. doi: 10.1002/(sici)1098-1136(200004)30: $2<134$ ::aid-glia3>3.0.co;2-3

Ledeboer, A., Breve, J. J., Wierinckx, A., van der Jagt, S., Bristow, A. F., Leysen, J. E., et al. (2002). Expression and regulation of interleukin-10 and interleukin10 receptor in rat astroglial and microglial cells. Eur. J. Neurosci. 16, 1175-1185. doi: 10.1046/j.1460-9568.2002.02200.x

Lee, Y. B., Nagai, A., and Kim, S. U. (2002). Cytokines, chemokines, and cytokine receptors in human microglia. J. Neurosci. Res. 69, 94-103. doi: 10.1002/jnr. 10253

Li, Q., Lan, X., Han, X., and Wang, J. (2018). Expression of Tmem119/Sall1 and Ccr2/CD69 in FACS-Sorted microglia- and monocyte/macrophage-enriched cell populations after intracerebral hemorrhage. Front. Cell Neurosci. 12:520. doi: 10.3389/fncel.2018.00520

Liu, C., Li, Y., Yu, J., Feng, L., Hou, S., Liu, Y., et al. (2013). Targeting the shift from M1 to M2 macrophages in experimental autoimmune encephalomyelitis mice treated with fasudil. PLoS One 8:e54841. doi: 10.1371/journal.pone.0054841

Lively, S., Lam, D., Wong, R., and Schlichter, L. C. (2018). Comparing effects of transforming growth factor betal on microglia from rat and mouse: transcriptional profiles and potassium channels. Front. Cell Neurosci. 12:115. doi: 10.3389/fncel.2018.00115

Lobo-Silva, D., Carriche, G. M., Castro, A. G., Roque, S., and Saraiva, M. (2016). Balancing the immune response in the brain: IL-10 and its regulation. J. Neuroinflamm. 13:297. doi: 10.1186/s12974-016-0763-768
Lodge, P. A., and Sriram, S. (1996). Regulation of microglial activation by TGFbeta. IL-10, and CSF-1. J. Leukoc. Biol. 60, 502-508. doi: 10.1002/jlb.60.4. 502

Luckoff, A., Scholz, R., Sennlaub, F., Xu, H., and Langmann, T. (2017). Comprehensive analysis of mouse retinal mononuclear phagocytes. Nat. Protoc. 12, 1136-1150. doi: 10.1038/nprot.2017.032

Magni, P., Ruscica, M., Dozio, E., Rizzi, E., Beretta, G., and Maffei Facino, R. (2012). Parthenolide inhibits the LPS-induced secretion of IL- 6 and TNF-alpha and NFkappaB nuclear translocation in BV-2 microglia. Phytother. Res. 26, 1405-1409. doi: $10.1002 /$ ptr.3732

Martin, E., El-Behi, M., Fontaine, B., and Delarasse, C. (2017). Analysis of microglia and monocyte-derived macrophages from the central nervous system by flow cytometry. J. Vis. Exp. 22:e55781. doi: 10.3791/55781

Martinez, F. O., Helming, L., and Gordon, S. (2009). Alternative activation of macrophages: an immunologic functional perspective. Annu. Rev. Immunol. 27, 451-483. doi: 10.1146/annurev.immunol.021908.132532

Martinez, F. O., Sica, A., Mantovani, A., and Locati, M. (2008). Macrophage activation and polarization. Front. Biosci. 13:453-461. doi: 10.2741/2692

McMurran, C. E., Jones, C. A., Fitzgerald, D. C., and Franklin, R. J. (2016). CNS remyelination and the innate immune system. Front. Cell Dev. Biol. 4:38. doi: $10.3389 /$ fcell.2016.00038

Michelucci, A., Heurtaux, T., Grandbarbe, L., Morga, E., and Heuschling, P. (2009). Characterization of the microglial phenotype under specific pro-inflammatory and anti-inflammatory conditions: effects of oligomeric and fibrillar amyloidbeta. J. Neuroimmunol. 210, 3-12. doi: 10.1016/j.jneuroim.2009.02.003

Mikita, J., Dubourdieu-Cassagno, N., Deloire, M. S., Vekris, A., Biran, M., Raffard, G., et al. (2011). Altered M1/M2 activation patterns of monocytes in severe relapsing experimental rat model of multiple sclerosis. Amelioration of clinical status by M2 activated monocyte administration. Mult. Scler. 17, 2-15. doi: $10.1177 / 1352458510379243$

Mildner, A., Huang, H., Radke, J., Stenzel, W., and Priller, J. (2017). P2Y12 receptor is expressed on human microglia under physiological conditions throughout development and is sensitive to neuroinflammatory diseases. Glia 65, 375-387. doi: 10.1002/glia.23097

Mizuno, T., Sawada, M., Marunouchi, T., and Suzumura, A. (1994). Production of interleukin-10 by mouse glial cells in culture. Biochem. Biophys. Res. Commun. 205, 1907-1915. doi: 10.1006/bbrc.1994.2893

Moore, K. W., de Waal Malefyt, R., Coffman, R. L., and O'Garra, A. (2001). Interleukin-10 and the interleukin-10 receptor. Annu. Rev. Immunol. 19, 683765. doi: 10.1146/annurev.immunol.19.1.683

Nadeau, S., and Rivest, S. (2000). Role of microglial-derived tumor necrosis factor in mediating CD14 transcription and nuclear factor kappa B activity in the brain during endotoxemia. J. Neurosci. 20, 3456-3468. doi: 10.1523/JNEUROSCI.2009-03456.2000

Nimmerjahn, A., Kirchhoff, F., and Helmchen, F. (2005). Resting microglial cells are highly dynamic surveillants of brain parenchyma in vivo. Science 308, 1314-1318. doi: 10.1126/science.1110647

Norden, D. M., Fenn, A. M., Dugan, A., and Godbout, J. P. (2014). TGFbeta produced by IL-10 redirected astrocytes attenuates microglial activation. Glia 62, 881-895. doi: 10.1002/glia.22647

Ohsawa, K., and Kohsaka, S. (2011). Dynamic motility of microglia: purinergic modulation of microglial movement in the normal and pathological brain. Glia 59, 1793-1799. doi: 10.1002/glia.21238

Orihuela, R., McPherson, C. A., and Harry, G. J. (2016). Microglial M1/M2 polarization and metabolic states. Br. J. Pharmacol. 173, 649-665. doi: 10.1111/ bph.13139

Peng, H., Geil Nickell, C. R., Chen, K. Y., McClain, J. A., and Nixon, K. (2017). Increased expression of M1 and M2 phenotypic markers in isolated microglia after four-day binge alcohol exposure in male rats. Alcohol 62, 29-40. doi: 10.1016/j.alcohol.2017.02.175

Ren, M., Guo, Q., Guo, L., Lenz, M., Qian, F., Koenen, R. R., et al. (2010). Polymerization of MIP-1 chemokine (CCL3 and CCL4) and clearance of MIP1 by insulin-degrading enzyme. EMBO J. 29, 3952-3966. doi: 10.1038/emboj. 2010.256

Robinson, A. P., White, T. M., and Mason, D. W. (1986). Macrophage heterogeneity in the rat as delineated by two monoclonal antibodies MRC OX-41 and MRC OX-42, the latter recognizing complement receptor type 3 . Immunology 57, 239-247. 
Samoilova, E. B., Horton, J. L., and Chen, Y. (1998). Acceleration of experimental autoimmune encephalomyelitis in interleukin-10-deficient mice: roles of interleukin-10 in disease progression and recovery. Cell Immunol. 188, 118124. doi: 10.1006/cimm.1998.1365

Satoh, J., Kino, Y., Asahina, N., Takitani, M., Miyoshi, J., Ishida, T., et al. (2016). TMEM119 marks a subset of microglia in the human brain. Neuropathology 36, 39-49. doi: 10.1111/neup.12235

Scheiblich, H., Schlutter, A., Golenbock, D. T., Latz, E., Martinez-Martinez, P., and Heneka, M. T. (2017). Activation of the NLRP3 inflammasome in microglia: the role of ceramide. J. Neurochem. 143, 534-550. doi: 10.1111/jnc.14225

Seo, D. R., Kim, K. Y., and Lee, Y. B. (2004). Interleukin-10 expression in lipopolysaccharide-activated microglia is mediated by extracellular ATP in an autocrine fashion. Neuroreport 15, 1157-1161. doi: 10.1097/00001756200405190-00015

Sheridan, G. K., and Murphy, K. J. (2013). Neuron-glia crosstalk in health and disease: fractalkine and CX3CR1 take centre stage. Open Biol. 3:130181. doi: 10.1098/rsob.130181

Sobin, C., Montoya, M. G., Parisi, N., Schaub, T., Cervantes, M., and Armijos, R. X. (2013). Microglial disruption in young mice with early chronic lead exposure. Toxicol. Lett. 220, 44-52. doi: 10.1016/j.toxlet.2013.04.003

Spittau, B., Wullkopf, L., Zhou, X., Rilka, J., Pfeifer, D., and Krieglstein, K. (2013). Endogenous transforming growth factor-beta promotes quiescence of primary microglia in vitro. Glia 61, 287-300. doi: 10.1002/glia.22435

Suh, H. S., Zhao, M. L., Derico, L., Choi, N., and Lee, S. C. (2013). Insulin-like growth factor 1 and 2 (IGF1, IGF2) expression in human microglia: differential regulation by inflammatory mediators. J. Neuroinflamm. 10, 37. doi: 10.1186/ 1742-2094-10-37

Sukhorukova, E. G., Zakhriapin, M. S., Anichkov, N. M., and Korzhevskii, D. E. (2012). Microglia detection in the brain preparations after long-term storage in formalin. Morfologiia 142, 68-71.

Tang, Y., and Le, W. (2016). Differential Roles of M1 and M2 microglia in neurodegenerative diseases. Mol. Neurobiol. 53, 1181-1194. doi: 10.1007/ s12035-014-9070-9075

Taylor, R. A., Chang, C. F., Goods, B. A., Hammond, M. D., Mac Grory, B., Ai, Y., et al. (2017). TGF-betal modulates microglial phenotype and promotes recovery after intracerebral hemorrhage. J. Clin. Invest. 127, 280-292. doi: 10. 1172/JCI88647

Torres-Platas, S. G., Comeau, S., Rachalski, A., Bo, G. D., Cruceanu, C., Turecki, G., et al. (2014). Morphometric characterization of microglial phenotypes in human cerebral cortex. J. Neuroinflamm. 11:12. doi: 10.1186/1742-2094-11-12
Voet, S., Mc Guire, C., Hagemeyer, N., Martens, A., Schroeder, A., Wieghofer, P., et al. (2018). A20 critically controls microglia activation and inhibits inflammasome-dependent neuroinflammation. Nat. Commun. 9:2036. doi: 10. 1038/s41467-018-04376-5

Williams, K., Dooley, N., Ulvestad, E., Becher, B., and Antel, J. P. (1996). IL-10 production by adult human derived microglial cells. Neurochem. Int. 29, 55-64. doi: 10.1016/0197-0186(95)00138-7

Xiao, B. G., Bai, X. F., Zhang, G. X., and Link, H. (1998). Suppression of acute and protracted-relapsing experimental allergic encephalomyelitis by nasal administration of low-dose IL-10 in rats. J. Neuroimmunol. 84, 230-237. doi: 10.1016/S0165-5728(97)00264-6

Yamasaki, R., Lu, H., Butovsky, O., Ohno, N., Rietsch, A. M., Cialic, R., et al. (2014). Differential roles of microglia and monocytes in the inflamed central nervous system. J. Exp. Med. 211, 1533-1549. doi: 10.1084/jem.20132477

Yang, J., Jiang, Z., Fitzgerald, D. C., Ma, C., Yu, S., Li, H., et al. (2009). Adult neural stem cells expressing IL-10 confer potent immunomodulation and remyelination in experimental autoimmune encephalitis. J. Clin. Invest. 119, 3678-3691. doi: 10.1172/JCI37914

Zhang, X., Koldzic, D. N., Izikson, L., Reddy, J., Nazareno, R. F., Sakaguchi, S., et al. (2004). IL-10 is involved in the suppression of experimental autoimmune encephalomyelitis by CD25+CD4+ regulatory T cells. Int. Immunol. 16, 249256. doi: 10.1093/intimm/dxh029

Zhou, T., Huang, Z., Sun, X., Zhu, X., Zhou, L., Li, M., et al. (2017). Microglia polarization with $\mathrm{M} 1 / \mathrm{M} 2$ phenotype changes in $\mathrm{rd} 1$ mouse model of retinal degeneration. Front. Neuroanat. 11:77. doi: 10.3389/fnana.2017.00077

Zoller, T., Schneider, A., Kleimeyer, C., Masuda, T., Potru, P. S., Pfeifer, D., et al. (2018). Silencing of TGFbeta signalling in microglia results in impaired homeostasis. Na.t Commun. 9:4011. doi: 10.1038/s41467-018-06224-y

Conflict of Interest: The authors declare that the research was conducted in the absence of any commercial or financial relationships that could be construed as a potential conflict of interest.

Copyright (C) 2019 Laffer, Bauer, Wasmuth, Busch, Jalilvand, Thanos, Meyer zu Hörste, Loser, Langmann, Heiligenhaus and Kasper. This is an open-access article distributed under the terms of the Creative Commons Attribution License (CC BY). The use, distribution or reproduction in other forums is permitted, provided the original author(s) and the copyright owner(s) are credited and that the original publication in this journal is cited, in accordance with accepted academic practice. No use, distribution or reproduction is permitted which does not comply with these terms. 